\section{Conjunctive Adverbials Used in Popular Scientific Articles}

\begin{abstract}
ABSTRAK
Cohesion is an essential component of discourse that will help the readers comprehend the articles' flow idea. Conjunctive adverbial is one of the cohesive devices that is commonly used in academic proses. This research aims to observe the forms, the sentential positions, and the cohesive meaning of conjunctive adverbials. Popular scientific articles are chosen to be data sources. The articles were downloaded from scientific magazines. Eighteen articles were from National Geography, and forty-six articles were from Psychology Today. Corpus linguistics is used as the approach of this study. The data are processed using Wordsmith 4 apps. The data selected are tabulated in Ms. Excel and analyzed using cohesion theory suggested by Halliday and Hasan (1976). The results show that conjunctive adverbials are dominated in word forms and followed by phrase forms in both magazines. The sentential positions of conjunctive adverbials are most frequently placed in an initial position followed by the magazines' medial positions. The end position of conjunctive adverbials is not found. The most frequent conjunctive adverbial function is adversative, and the least frequent is causal in both magazines.
\end{abstract}

Keywords: conjunctive adverbials; discourse markers; popular scientific articles

\title{
INTRODUCTION
}

Cohesion is an essential component in forming the idea of discourse. Halliday and Hasan (1976) define cohesion as a semantic relation referring to meaning in the text. Cohesion integrates elements in the text to form an overall sense. Cohesion can be constructed using several cohesive devices. Celce-Murcia and Larsen-Freeman (1999) define a cohesive device as a lexical expression, a proposition between sentences. This device allows the reader to infer the relation between two segments of discourse. Furthermore, Celce-Murcia and Larsen-Freeman divide cohesive devices into three types, namely, coordinating conjunctions (e.g., and, or), subordinating conjunctions (e.g., because, if), and conjunctive adverbials (for example, however, thus, moreover) (Celce-Murcia and Larsen-Freeman 1999). Halliday \& Hasan (1976) divided conjunctive adverbials into four: additive, additive, causal, and temporal.

Each conjunctive adverbial has different cohesive functions, thus uniting the logical flow of ideas in an article. The unity of the thought will help readers to follow the arguments presented easily. However, implementing those cohesive devices in academic writing is not easy. Kurniawan et al. found that the unity of ideas using cohesive devices in research articles is still tricky for second language learners to apply (Kurniawan, Ruswan, and Cahyowati 2019). In addition, many second language learning students use conjunctive adverbials as cohesive devices inappropriately (Janulienè and Dziedravičius 2015; An and Xu 2018). Chen revealed that students need to carefully choose conjunctive adverbials to ensure their writing's logical arguments (Chen 2006). This conjunctive adverbial is interested in observing deeper related to conjunctive adverbials and the discourse's cohesive functions.

The use of conjunctive adverbials as a connective device in the discourse is typically different. Jackson (2013) argues that conjunctive adverbials are generally used in academic writing. Even so, those types of articles used have different types caused by the other register and genre. Research articles and popular scientific articles, for example, are academic writing that has different registers and genres. Articles in academic writing are written with particular terminology, complete sentences, formal Scientific Articles. Deskripsi Bahasa Vol. 3(2). 2020, pp. 137-146. https://jurnal.ugm.ac.id/v3/db 
language, passive voice, and other additional tools (Fraser 2015). Research articles, for example, is one of the academic writing that uses many conjunctive adverbials. In reverse, a popular scientific article is one type of popular articles that use fewer conjunctive adverbials compared to research articles. Parkinson (2001: 300) divides popular articles into two genres: issue reports (more common for popular science articles) and opinion pieces. Popular scientific articles discuss issue reports like research article reports on new findings that have not yet the status of fact or have not, however, accepted by the research community. These articles describe attributes using the expert or scientist's quotes to perform the articles' argument (Parkinson 2001).

The variety of discourse markers used implies a variety of different meanings. Lapshinova-Koltunski \& Kunz (2014) found that their research's biggest challenge is identifying the conjunctive adverbials' form and function. The adverbs used can have different cohesive and non-cohesive functions (Lapshinova-Koltunski and Kunz 2014). Another study found that students misused conjunctive adverbials and were limited due to lower comprehension in distinguishing registers (An and Xu 2018). Each discourse has a different type of cohesive marker. Discourse markers used in spoken language, for example, are different from discourse markers used in articles. Crible et al. (2019) revealed that the discourse markers most often used in TED Talks in five languages (English, Czech, French, Hungarian, and Lithuanian) are and, but, so. Differences in registers of discourse will affect the discourse markers used in the discourse.

The problems found in the previous study becomes the basis of this study to find out (1) the types of conjunctive adverbials, (2) the sentential positions of Conjunctive adverbials, and (3) the cohesive meaning of conjunctive adverbials in popular scientific articles. The conjunctive adverbials investigated in this article are the expressions that function as connectors between sentences; coordinating conjunction and subordinating conjunction between sentences are not included. The study of conjunctive adverbial is nearly important and potentially can contribute to the development of the writing study, especially in academic writing. Popular scientific articles are selected as the data sources due to the popular scientific article's scarcity as the previous study's data sources. The earliest studies mostly used research articles as data sources because adverbial conjunction is commonly found there. This finding will potentially find out the conjunctive adverbial use in the different registers of academic writings.

This research used a corpus linguistic approach to process the data. The data sources used were the popular scientific articles published by scientific magazines National Geography and Psychology Today. Those popular magazines were chosen due to the high popularity and the open-access of those articles. The sample articles were selected based on the articles' theme related to the "History and Cultures". The time publishing limited the data sources from July to November 2020. There were 28 articles published by National Geography retrieved from nationalgeographic.com. And, 46 articles published by Psychology Today recovered from psychologytoday.com. The length of the articles causes the different numbers of total articles in each magazine. The total words of articles limit the data sources. Ms. Words was used to count the full words of the articles.

\begin{tabular}{lcc}
\multicolumn{1}{c}{ Popular Magazines } & Total Articles & Total Words \\
\hline National Geography & 28 & 46.683 \\
Psychology Today & 46 & 46.710 \\
\hline
\end{tabular}

The quantitative analyses determine the percentages of the frequency used, the sentential position, and the cohesive device of conjunctive adverbials found in the popular scientific articles. The data found were normalized by the ratio of frequency per 10.000 words (Biber and Reppen 2015).

\section{$\mathrm{FPW}=$ $\mathrm{RF} \times 10.000$ \\ Total Words}

The data were processed using Wordsmith 4 application to find out the frequency used of conjunctive adverbials. Coding is necessary to categorize the data. The frequency was coded FPW (Frequency per 10.000 words), RF (Raw frequency), and \% (\% of overall Conjunctive adverbials used). The percentage of conjunctive adverbials (CAs) is counted by 


Percentage $(\%)=\quad \frac{\text { RF of CAs }}{\text { Total CAs }} \times 100 \%$

\section{RESULT AND DISCUSSION}

A total of 94 and 188 Conjunctive adverbials were identified from two magazines of popular scientific articles. Ninety-four conjunctive adverbials were found in National Geography articles, and 188 were found in Psychology Today's articles. The frequency use of conjunctive adverbials is presented in Table 1.

Table 1. The Total Number of Conjunctive Adverbials in Popular Scientific Articles

\begin{tabular}{lcc}
\hline Category & National Geography & Psychology Today \\
\hline Raw Frequency & 94 & 188 \\
Frequency Per 10.000 Word & 20.1 & 40.2 \\
\hline
\end{tabular}

As shown in Table 1, the popular scientific articles written in National Geography and Psychology Today have a different number of conjunctive adverbials. National Geography used fewer Conjunctive adverbials in its articles in normal frequency (20.1) while Psychology Today used twice higher than National Geography (40.2). These data show significant differences in conjunctive adverbials use by the same register, popular scientific articles. Register affects conjunctive adverbials in article writing (Chen 2006; An and Xu 2018; Crible et al. 2019). The previous study proves that the register has the essential roles in selecting the appropriate conjunctive adverbials. However, the data found in this article show that the articles in the same register have a different use of conjunctive adverbials. Psychology Today use conjunctive adverbials more frequently than National Geography. The external factors may influence the conjunctive adverbial selections in each article's writing.

\section{The Forms of Conjunctive Adverbials}

Halliday \& Hasan (1976) define conjunctive adverbial as a conjunctive adjunct. According to Halliday \& Hasan (1976), there are three types of conjunctive adjuncts: adverbs, other compound adverbs, and prepositional phrases. The main classifications are then divided in more detail. The adverbs are divided into two, namely, simple adverbs and compound adverbs. Simple adverbs are the coordinating conjunctions like and, but, so, while compound adverbs are the adverb expressions like accordingly, subsequently, actually, therefore, thereupon, whereat. The second classification is adverbs as other compound adverbs like furthermore, nevertheless, anyway, instead, besides. And, the last category is a prepositional phrase that functions as connectives like, on the contrary, as a result, in addition. Further, Jackson (2013) classifies the types of conjunctive adverbials into five, namely simple adverbs, adverbs particles, prepositions, noun phrases, and clauses. Those classifications were then generalized to three types: simple adverbs (words), phrases, and clauses.

The following table presents the forms of conjunctive adverbials used in popular scientific articles. The tables are presented in Table 2, accompanied by the raw frequency (RF), frequency per 10.000 words (FPW) or normal frequency, and the percentage use of Conjunctive adverbials (\%).

Table 2. The Forms of Conjunctive adverbials in Popular Scientific Articles

\begin{tabular}{lll}
\hline Category & National Geography & Psychology Today \\
\hline Raw Frequency of Words & 59 & 99 \\
Frequency Per 10.00o Word & 12.6 & 21.2 \\
Percentage & $62.8 \%$ & $52.7 \%$ \\
\hline
\end{tabular}


Ani Malichatun \& Tofan Dwi Hardjanto

\begin{tabular}{lll}
\hline Raw Frequency of Phrases & 35 & 82 \\
Frequency Per 10.000 Word & 7.5 & 17.6 \\
Percentage & $37.2 \%$ & $43.6 \%$ \\
\hline Raw Frequency of Clauses & 0 & 7 \\
Frequency Per 10.000 Word & 0.0 & 1.5 \\
Percentage & $0.0 \%$ & $3.7 \%$ \\
\hline
\end{tabular}

Table 2 reveals the forms of conjunctive adverbials in popular scientific articles. Psychology Today uses more varied conjunctive adverbials in its articles compared to National Geography. Overall, the conjunctive adverbials used in both magazines are dominated by words followed by the phrase. National Geography is found to use 12.6, and Psychology uses a higher number than National Geography as many as 21.2 per 10.000 words. Here are some examples of conjunctive adverbials found in both articles in the form of words.

Data examples from National Geography

(1.1) Nevertheless, Ousamequin served an important role for all Wampanoag by leading them in war against the Narragansett, who lived on the west side of Narragansett Bay.

(1.2) The images of real mothers and their real sons do not depict real death. Rather, they capture the constancy and ubiquity of that fear-the ringing in our Black mothers' ears that never goes away.

(1.3) The British abandoned it with little decorum when the Japanese invaded. (They ran for their lives, pell-mell.) Later, it was the Japanese turn to evacuate Mawlaik when their advance into India collapsed.

Data examples from Psychology Today

(2.1) Conversely, just reading a post on Facebook or looking at a tweet will not engender the same sense of belonging.

(2.2) We've become so polarized that if you even mention your political party or your political persuasion, you risk being attacked. Again, when talking about politics, focusing on facts is essential.

(2.3) The least of our civic duties is voting in every election, as many of us should answer the call to run for office or take on other leadership roles to advance our communities. Nonetheless, we know that if everyone simply voted, we could ensure that there are diverse perspectives and voices heard.

The second highest frequency of conjunctive adverbial used in both articles is phrase forms. The phrase forms of conjunctive adverbials are found 7.5 in National Geography and 17.6 in Psychology Today in normal frequency. Here are some examples of conjunctive adverbials in the phrase forms.

Data examples from National Geography

(1.4) These voyages presented both opportunity and grave danger for the Wampanoag. On the one hand, Europeans offered a variety of dazzling trade goods including metal tools and weapons, brightly colored cloth, and glass beads. On the other hand, Europeans tended to respond violently to real or imagined Indian threats.

(1.5) Once heated up, they release the heat only slowly into the surrounding air like a hot, stale breath. Trees and plants, on the other hand, cool cities down.

(1.6) "We kept showing this map to different groups, and it was like a Rorschach test of their background and interests," she says. Health experts, for example, noticed that the covenant-free, redlined areas of the map corresponded disturbingly well with the areas they knew had high asthma rates and low birth weights-conditions associated with exposure to air pollution and other environmental hazards. 
Data examples from Psychology Today

(2.4) Following the interaction and conversation about the assigned political topic, participants rated (a) themselves and (b) other group members on personality questionnaires, including intellectual humility. In addition, researchers coded for behaviors in the interaction, such as the number of interjections one made, the valence of these interjections (e.g., positive, negative), and the number of inquiries one made.

(2.5) The psychologists are careful to point out that they do not claim that traditional masculinity is inherently depraved. For instance, they point out that being assertive, competitive, and strong (stereotypically masculine traits) can be beneficial across many life domains.

(2.6) What we found was that that extraversion advantage disappeared when you put social skills into the equation. So in other words, it's not just the ones who talk the most that make the best leaders; it's the skilled communicators.

The form of conjunctive adverbial in clause forms is not found in the article written by National Geography, and only a small number of clause forms are found in Psychology Today (1.5 per 1000 words). Data (2.7) is the example of a finite clause as conjunctive adverbials.

(2.7) Most nonviolent protests are normative, that is, they are in line with what people think is acceptable for a protest, e.g., peacefully assembling and marching.

The data above reveal that words are the broadest form of conjunctive adverbials used in popular scientific articles in National Geography and Psychology Today. This finding is relevant to the previous result study found by Erisha (2019). She found that the highest percentage of conjunctive adverbial found was word form followed by phrase and a small number of clauses in English research articles. Erisha found that $78 \%$ of conjunctive adverbials were in word forms, $19 \%$ in phrase forms, and $3 \%$ in clause forms (Erisha 2019). In line with this finding, conjunctive adverbials as cohesive devices function to unite the discourse's idea. Hence, the more straightforward the conjunctive adverbials used, the easier the readers understand the discourse's flow idea.

\section{The Sentential Position of Conjunctive Adverbials}

Conjunctive adverbials are flexibly positioned in the sentences. Halliday \& Hassan (1976) define adverbials conjunctions in three places, initial, medial, and final. Quirk et al. (1985) and Greenbaum \& Quirk (1990) also provide examples of conjunctive adverbials' various sentential positions. The three prominent positions occupied by the conjunctive adverbial in the sentence are the initial $(I)$ position, medial $(M)$ position, and end $(E)$ position. The medial and end positions are then classified in more detail in each category. There are three medial positions, namely initial $(i M)$, medial $(m M)$, and end $(e M)$. The end positions are varied in the initial end $(i E)$ and end $(E)$.

The following table presents the sentential position of conjunctive adverbials in the sentences. The initial and medial positions are found in this article. The end position is not found either in National Geography or Psychology Today.

Table 3. The Sentential Position of Conjunctive adverbials in Popular Scientific Articles

\begin{tabular}{lll}
\hline Category & National Geography & Psychology Today \\
\hline RF of Initial Position & 77 & 49 \\
Frequency Per 10.00o Word & 16.5 & 31.9 \\
Percentage & $81.9 \%$ & $79.3 \%$ \\
\hline RF of Medial Position & 17 & 39 \\
Frequency Per 10.00o Word & 3.6 & 8.3 \\
Percentage & $18.1 \%$ & $20.7 \%$ \\
\hline
\end{tabular}

The sentential position of conjunctive adverbials in popular scientific articles is dominated in the initial positions (I) in National Geography $81.9 \%$ with a normal frequency of 16.5 and Psychology Today $79.3 \% 31.9$ per 10.000 words. Those sentential positions can be seen from the data example 
(1.1) to (1.4) for National Geography and data examples (2.1) to (2.6) for Psychology Today. The second-frequently use conjunctive adverbials are medial positions. Swan (1988) found that conjunctive adverbials' most frequent positions are in initial positions and medial positions. The medial position of conjunctive adverbials can be seen in the data examples (1.5), (1.6), (1.7), and (2.8). These medial positions are commonly found after the sentences' subject (1.5) and (1.6). Two commas commonly separate the medial positions before and after the conjunctive adverbials. The data example of (1.7) has different positions. The conjunctive adverbial of however places before subject but after the adverb of place of the sentence. Another data (2.8) has a position after the verb of the sentence, or in general, it is called middle position (MM).

End sentential position (E) of conjunctive adverbials in popular scientific articles written by both magazines are not found. This finding implies that the end-sentential position of conjunctive adverbials is rarely used in popular scientific articles. Greenbaum (1969) agrees that sentence adverbial typically occur in initial positions. That argument is also supported by the finding of Swan (1988). Swan found that the occurrences of sentential adverbs tend to appear in initial positions and the post-verbal positions (medial positions) (Swan 1988).

The initial position is generally used to connect ideas from the previous sentence to the following sentences. Jackson (2013) explains that conjunctive adverbials join sentences in separate written units. Jackson's term of the written unit is a stretch of writing beginning with the capital letter and end with the full-stop (Jackson 2013). The initial position is commonly used because it directly connects the previous and the following sentences to ease popular scientific articles' understanding of the articles' flow idea. Swan (1988) said, "that items when being established as SA must be stabilized in the initial position." Swan added that non-initial sentential adverbs (middle positioned-adverbs) show an erotic pattern and behavior, but in general, moved steadily to the right. The available shift is SXV to SVX syntax (Kohonen 1978 in Swan 1988).

\section{The Cohesive Functions of Conjunctive Adverbials}

The cohesive functions of conjunctive adverbials are based on the semantic meaning. Jackson (2013) classifies conjunctive adverbials in English into seven types: listing, summative, appositive, resultive, inferential, contrastive, and transitional. More simply, Halliday \& Hasan (1976) classified conjunctive adverbials into four main types: additive, adversative, causal, and temporal. Furthermore, Halliday \& Hasan (1976) categorized each type of conjunctive adverbial into more specific categories. The cohesive function of conjunctive adverbials in this article are classified into four categories based on Halliday \& Hasan (1976) classification.

The following Table 4 presents the cohesive functions of conjunctive adverbials found in popular scientific articles. There are four cohesive functions adopted in this article, as described in Table 4. Both articles' cohesive functions are as follows.

Table 4. The Cohesive Functions of Conjunctive adverbials in Popular Scientific Articles

\begin{tabular}{lll}
\hline Cohesive Functions & National Geography & Psychology Today \\
\hline Additive & $9.6 \%$ & $35.1 \%$ \\
Adversative & $50.0 \%$ & $39.4 \%$ \\
Causal & $8.5 \%$ & $8.0 \%$ \\
Temporal & $31.9 \%$ & $17.6 \%$ \\
\hline
\end{tabular}

It can be seen from Table 4 that the most frequent cohesive functions of conjunctive adverbials in popular scientific articles are adversative both in National Geography (50.0\%) and Psychology Today (39.4\%). Here are some examples of the adversative conjunctive adverbials found in both magazines.

The three most frequently used adversative conjunctive adverbials found in National Geography are as follows. 
(1.7) In the short term, it had the desired effect of achieving Wampanoag independence from the Narragansett, enriching his followers with English goods, and consolidating his authority. In the long term, however, the consequences were disastrous.

(1.8) But Grijalva said she and the other workers (nearly all of them Latino) didn't worry so much about themselves; instead, they were concerned about the elderly residents in their care, and the possibility that one of the workers might bring the deadly virus to them.

(1.9) Still, for first-person interpretation, most museum experts think using "blind casting" with a Black George Washington (à la the musical Hamilton) or a Latina Harriet Tubman won't help people understand history better.

The three most frequently used adversative conjunctive adverbials found in Psychology Today are as follows.

(2.8) Any healthcare professional will immediately recognize the similarities between the concept of WELLBYs and the concepts of Quality-Adjusted Life-Years (QALYs) and DisabilityAdjusted Life-Years (DALYs). There are, however, substantial differences.

(2.9) The more time you spend on social media, the more money they make. In fact, the information you're seeing often is not true, so you have to fact-check it.

(2.10) I need to stop trying to understand why half of my neighbors see things so differently from how I do. Instead, I need to empathize with how the divisions feel to those on the other side.

These data imply that the general use of conjunctive adverbial in writing popular scientific articles tends to be similar. The logical idea that popular scientific articles want to explore has identical patterns. This finding is irrelevant to some previous studies done by An \& Xu (2018) and Chen (2006). An \& Xu (2018) did a study on a research article written by Chinese ESL, while Chen (2006) did a study on academic writing of advanced Taiwanese ELF learners. Both researched the use of conjunctive adverbial used in research articles. They found that the most frequently used adverbial conjunctive is additive. Therefore, the data found in this article tend to use adversative adverbial conjunctions. This finding implies that the popular scientific article uses adversative relation in delivering the idea. Adversative relations are used by the writer to demonstrate their idea in their writings inasmuch as the popular scientific article is argumentative writing. In line with Parkinson (2001), He found that popular scientific articles framed their ideas as a report on a debate between different researchers. As a result, adversative relations are more commonly used to deliver the fact in the articles.

The second positions of conjunctive adverbials found are temporal (17.6\%) for National Geography and additive (35.1\%) for Psychology Today. The second rank and the third rank of conjunctive adverbials cohesive functions are all different. This difference is due to the logical idea that tries to build in each article. However, the lowest frequency of conjunctive adverbials used in both National Geography and Psychology Today are the same. Causal relation has a low number used in the writing of the popular scientific article. This finding implies that popular scientific articles less inform the cause-effect and explain information in delivering the fact. Parkinson (2001) revealed that popular scientific articles, in general terms, tend to focus on the researchers, what they do and say (Parkinson 2001).

\section{The Most Frequently Use of Conjunctive Adverbials}

Adversative functions of conjunctive adverbials are found most frequently in both magazines. This adversative function is represented by the occurrence of some conjunctive adverbials such as, however, nevertheless, on the other hand, in other words, in fact, etc. Table 5 present the individual use of conjunctive adverbials with the percentage and normal frequency. The following table shows the list of 10 most frequently used conjunctive adverbials found in both magazines.

Table 5. The List of 10 Most Frequently Used Conjunctive Adverbials in Popular Scientific Articles

\begin{tabular}{lcccccccc}
\hline \multicolumn{4}{c}{ National Geography } & \multicolumn{4}{c}{ Psychology Today } \\
\hline $\begin{array}{l}\text { Conjunctive } \\
\text { adverbials }\end{array}$ & RF & FPW & $\%$ & $\begin{array}{l}\text { Conjunctive } \\
\text { adverbials }\end{array}$ & RF & FPW & $\%$ \\
\hline
\end{tabular}


Ani Malichatun \& Tofan Dwi Hardjanto

\begin{tabular}{llllllll}
\hline however & 13 & 2.8 & 13.8 & however & 24 & 5.1 & 16.0 \\
then & 13 & 2.8 & 13.8 & for examples & 22 & 4.7 & 14.7 \\
Still & 7 & 1.5 & 7.4 & in fact & 10 & 2.1 & 6.7 \\
Instead & 7 & 1.5 & 7.4 & in addition & 9 & 1.9 & 6.0 \\
for examples & 6 & 1.3 & 6.4 & that is & 7 & 1.5 & 4.7 \\
at the same time & 5 & 1.1 & 5.3 & thus & 7 & 1.5 & 4.7 \\
though & 4 & 0.9 & 4.3 & still & 7 & 1.5 & 4.7 \\
at first & 4 & 0.9 & 4.3 & instead & 7 & 1.5 & 4.7 \\
Ons & 4 & 0.9 & 4.3 & for instance & 6 & 1.3 & 4.0 \\
on the other hand & 3 & 0.6 & 3.2 & as a result & 6 & 1.3 & 4.0 \\
\hline
\end{tabular}

There are various kinds of conjunctive adverbial used in popular scientific articles. A total of 28 and 49 conjunctive adverbials are used in National Geography and Psychology Today. The finding implies that Psychology Today tends to use more various conjunctive adverbials in its article writing. The most frequently used conjunctive adverbials are however both in National Geography and Psychology. In addition, this high-frequency use of conjunctive adverbials is noticeable in Psychology Today, where however occurs 5.1 times per 10.000 words and accounts for $16 \%$ of total adverbial used. In National Geography, however appears on a second of the occurrence in Psychology Today.

Similarly, this finding is in line with some previous study found that however is the most frequently used conjunctive adverbials in research articles (Matte and Laísa 2018; Chen 2006). Both Chen (2006) and Matte \& Sarmento (2018) studied conjunctive adverbial in a research article written by EFL students. They found that however is the most frequently used conjunctive adverbials by ELF students.

However is the only conjunctive adverbials that seem to appear in the same rank. The second and the following position of the ten most frequently used conjunctive adverbials are significantly different. For example, the only adverbial conjunction appears after however in the ten most frequent conjunctive adverbials. This finding implies that both National Geography and Psychology Today select conjunctive adverbials for their article writing differently. The five least conjunctive adverbials used in National Geography are in other words, otherwise, meanwhile, in the meantime, and on the second. Differently, Psychology Today uses because of this, as a matter of fact, by contrast, in this way, and subsequently in small numbers.

\section{CONCLUSION}

There are various types of conjunctive adverbial used in popular scientific articles. A total of 28 and 49 conjunctive adverbials are found in National Geography and Psychology Today. The conjunctive adverbials found are various and dominated by word forms in both magazines. The phrase forms are in the second position. The small number of clause forms are found only in Psychology Today. These findings are relevant to Elrisha (2019) finding and directly answer the first research questions. Also, it shares the idea that word forms are the broadest form of conjunctive adverbials used either in popular scientific articles or other research articles.

Various conjunctive adverbials found a place in two positions: initial position (I) and medial position (M). There was not found conjunctive adverbial positioned in the end position. The initial position is the most common position for conjunctive adverbial to take place in popular scientific articles. This finding answers the second research question about the sentential position of conjunctive adverbials. The end position is rarely found for conjunctive adverbial. Erisha (2019) also found no conjunctive adverbial placed in the final/end position. She found that conjunctive adverbials' dominant position is in the initial position (87\%) (Erisha 2019). It can be concluded that the initial position is the most common position placed for conjunctive adverbial both in popular scientific articles or research articles. 
The conjunctive adverbial's cohesive functions are additive, adversative, causal, and temporal (Halliday and Hassan 1976). The most frequent conjunctive adverbials in popular scientific articles are adversative both in National Geography and Psychology Today. However, for instance, is the highest percentage of Conjunctive adverbials found in both articles. This finding is in reverse with some previous studies working on research articles. Those studies found that conjunctive adverbials' most frequently used adverbials are additive (Chen 2006; An and Xu 2018). Therefore, the least often used conjunctive adverbials in both magazines are the same. $A$ causal conjunctive adverbial is the least frequent use of conjunctive adverbials.

The third research question finding may imply that the research article's register and genre and popular scientific articles are different. Further, research articles and popular scientific articles are needed with the data sources from the same register but different in genre or possibly different data sources in the same register and genre. More extensive data sources in this typical research are also suggested for the next study to obtain more comprehensive research results.

\section{REFERENCES}

An, Xuehua, and Mingying Xu. 2018. "Conjunctive Adverbials in Chinese ESL Postgraduates' Expository Writing." Journal of Language Teaching and Research 9 (6). Academy Publication Co., LTD: 1243-50. https://go.gale.com/ps/i.do?p=AONE\&sw=w\&issn=17984769\&v=2.1\&it=r\&id=GALE\%7CA626 $124720 \&$ sid $=$ googleScholar\&linkaccess $=$ abs.

Biber, Douglas, and Randi Reppen. 2015. The Cambridge Handbook of English Corpus Linguistics.

Celce-Murcia, Marianne, and Diane Larsen-Freeman. 1999. "The Grammar Book: An ESL/EFL Teacher's Course. Second Edition." USA: Heinle \& Heinle Publisher.

Chen, Cheryl Wei-yu. 2006. "The Use of Conjunctive Adverbials in the Academic Papers of Advanced Taiwanese EFL Learners." International Journal of Corpus Linguistics 11 (1). John Benjamins: 113-30. doi:10.1075/ijcl.11.1.05che.

Crible, Ludivine, Ágnes Abuczki, Nijolè Burkšaitienè, Péter Furkó, Anna Nedoluzhko, Sigita Rackevičienè, Giedrè Valūnaitė Oleškevičienė, and Šárka Zikánová. 2019. "Functions and Translations of Discourse Markers in TED Talks: A Parallel Corpus Study of Underspecification in Five Languages." Journal of Pragmatics 142 (March): 139-55. doi:10.1016/j.pragma.2019.01.012.

Erisha, Norra. 2019. "Adverbial Konjungtif Antarkalimat Dalam Artikel Ilmiah Berbahasa Inggris." Master Thesis, Yogyakarta: Universitas Gadjah Mada. http://etd.repository.ugm.ac.id/penelitian/detail/178407.

Fraser, Bruce. 2015. "The Combining of Discourse Markers - A Beginning." Journal of Pragmatics, Interdisciplinary perspectives on pragmatics: A Festschrift for Jonathan Culpeper, 86 (September): 48-53. doi:10.1016/j.pragma.2015.06.007.

Greenbaum, Sidney. 1969. Studies in English Adverbial Usage. Miami: University of Miami Press.

Greenbaum, Sidney, and Randolph Quirk. 1990. A Student's Grammar of the English Language. Longman.

Halliday, Michael A, and Ruqaiya Hassan. 1976. Cohesion in English. London: Longman.

Jackson, Howard. 2013. Grammar and Meaning: A Semantic Approach to English Grammar. London: Routledge, Taylor and Francis.

http://public.ebookcentral.proquest.com/choice/publicfullrecord.aspx?p=1710719.

Janulienè, Aušra, and Justinas Dziedravičius. 2015. "On the Use of Conjunctive Adverbs in Learners' Academic Essays." Verbum 6 (o): 69-83. doi:10.15388/Verb.2015.6.8809.

Kurniawan, Eri, Dallyono Ruswan, and Avika Cahyowati. 2019. "Exploring Logical Connectors in Journals with Different Indexing Levels: A Comparison between International and National 
Ani Malichatun \& Tofan Dwi Hardjanto

Indexed Journals." Indonesian Journal of Applied Linguistics 9 (1): 76-84.

doi:10.17509/ijal.vgi1.16088.

Lapshinova-Koltunski, Ekaterina, and Kerstin Kunz. 2014. "Cohesive Conjunctions in English and German: Systemic Contrasts and Textual Differences." In Language and Computers, edited by Lieven Vandelanotte, Kristin Davidse, Caroline Gentens, and Ditte Kimps, 229-62.

Amsterdam: Rodopi.

Matte, Marine Laísa, and Marine Laísa. 2018. "A Corpus-Based Study of Connectors in Student Academic Writing." English for Specific Purposes World 20 (55): 1-21. http://espworld.info/Articles_55/MATTE_\%20SARMENTO_ESP_WORLD.pdf.

Parkinson, Jean. 2001. "Popular and Academic Genres of Science : A Comparison, with Suggestions for Pedagogical Applications." Dissertation, South Africa: University of Kwazulu-Natal. https://researchspace.ukzn.ac.za/handle/10413/5911.

Quirk, Randolph, Sidney Greenbaum, Geoffrey Leech, and Jan Svartvik. 1985. A Comprehensive Grammar of the English Language. London: Longman.

Swan, Toril. 1988. "The Development of Sentence Adverbs in English." Studia Linguistica 42 (1): 117. doi:10.1111/J.1467-9582.1988.TBoo782.X. 